\title{
The conceptual structure of irreality. A focus on non-exclusion-of-factuality as a conceptual and a linguistic category
}

\author{
Paola Pietrandrea \\ Università Roma Tre \\ pietrand@uniroma3.it
}

\author{
Author's address \\ Paola Pietrandrea \\ Dipartimento di Linguistica \\ Via Ostiense 236 \\ 00144 Roma
}

\begin{abstract}
Irreality and modality often converge in the literature. Nevertheless, there are grounds to keep the two notions separate. The effort of defining irreality in non-modal terms leads to redefine irreality as a supercategory encompassing three close conceptual domains concerned with the non-actualization of a SoA: counterfactuality, non-exclusion of factuality and non-referentiality. This article focuses on the linguistic relevance of non-exclusion of factuality in Italian. It is shown that non-exclusion of factuality is to be regarded as a defining component of the conceptual structure of a number of irrealis situations (hypothetical, concessive conditionals, alternative relations) and that it is semanticized (through intentional mechanisms of explicit coding, conventional implicature or invited inference) in the way Italian encodes other typically irrealis situations (counterfactual conditionals, optatives, recommendations). The categoriality of non-exclusion-of-factuality in Italian is discussed. Italian has an abstract complex constructional marker dedicated to the expression of non-exclusion of factuality: the construction magari + list, which is instantiated by a number of more specific constructions conveying specific instances of non-exclusion of factuality meaning (equipotential non-exclusion of factuality constructions, scalar non-exclusion of factuality constructions, scalar concessive conditional constructions, recommendation constructions, and, perhaps, optative constructions). The grammatical nature of this constructional marker is not to be excluded, even though, given the state of knowledge, it cannot be explicitly argued.
\end{abstract}

\section{Introduction}

The linguistic relevance of the opposition between reality and irreality is a hotly debated issue. As shown by Mauri \& Sansò (this volume - a), the lack of overt marking of reality status in some languages, the fact that certain situation types are marked as realis in a language and as irrealis in others and the vagueness of the characterization of irreality make this notion a weak candidate for the status of an autonomous semantic category. The most effective synthesis of the criticisms addressed against the category of reality status is provided by Bybee (1998), who writes:

"There is a conceptual domain that contains many ways in which a situation can be conceived of as unreal. In fact, it is largely coextensive with the domains of modality [...]. But perhaps lack of reality is not the most important feature of these domains; perhaps from the point of view of what people want to communicate, the more specific meanings such as obligation, permission, imperative, and possibility are more useful. A highly generalized notion such as "lacking in reality" is probably too abstract to be of much communicative use".

(Bybee 1998: 267). 
Given the weakness of the definition of reality status, Bybee proposes to regard what is commonly labeled as irreality - i.e. one of the two values of reality status - as the expression of some modal attitude.

In this article, a reappraisal of the notion of reality status and in particular of its irrealis value is proposed. This reappraisal is based on the theoretical assumption that irreality, which is commonly defined as the marking of the non actualization of a State of Affair (henceforth SoA) is in fact a very generic notion used to indicate different conceptual subdomains of non actualization such as (i) counterfactuality, i.e. the negation of the actualization of a SoA, (ii) non-exclusion-of-factuality, i.e. the indication that the actualization of the depicted SoA is not to be excluded on a par with other mutually exclusive options (henceforth we will refer to non-exclusion-of-factuality with the acronym NEF) and (iii) non-referentiality,. i.e. the lack of spatio-temporal specifications concerning the occurrence of a SoA.

The conceptual complexity of the notion of irreality is often disregarded. Similarly disregarded is the complexity of the conceptual structure ${ }^{1}$ of what are commonly defined "logically irrealis" situation types: hypotheses, orders, epistemic attitudes, concessions, wishes, etc.

Our analysis is based on the theoretical assumption that every logically irrealis situation (as well as, more generally, every conceptual notion) has a complex conceptual structure and that languages arbitrarily select the components of this conceptual structure to be made linguistically relevant, i.e. to be semanticized (see in this regard Mauri \& Sansò's (this volume - b) contribution on the conceptual structure of directives).

Assuming the complexity of the conceptual structure of the notion of irreality on the one hand and the complexity of the conceptual structure of irrealis situation types on the other sheds new light on our way of looking at the linguistic encoding of irreality. A refinement of the notion of irreality, in fact, provides elements for a more effective identification of its core properties, and consequently both for a neater distinction of this category from neighboring categories (such as modality) and for a better characterization of its communicative use. The appraisal of the complexity of the conceptual structure of irrealis situation types can explain many misalignments between the logical nature of a situation and its characterization in terms of realis/irrealis. Finally, and probably more importantly, given these premises it becomes possible at least to raise the issue of the grammatical nature of the category of irreality.

This article is organized as follows: a distinction between modality and irreality is proposed in $\$ 2$. This entails the necessity of redefining irreality in non modal terms. This leads to a redefinition of irreality as a supercategory encompassing counterfactuality, NEF and non-referentiality (\$3). The rest of the article focuses on NEF. The semantic relevance of this notion for many typically irrealis constructions (hypothetical conditionals, counterfactual conditionals, concessive conditionals, optatives, directives, alternative relations) is studied in $\$ 4$, with a focus on Italian. The issue of the grammatical status of this notion is raised in $\$ 5$, where it is shown that Italian does have a construction dedicated to the encoding of NEF. The issue of the grammatical vs. lexical nature of this construction is addressed (but not resolved) in $\S 6$. Some theoretical conclusions are drawn in $§ 7$.

\footnotetext{
1 The notion of 'conceptual structure' is theoretically discussed by Prandi (2004), who founds his 'philosophical grammar' on the complementation between formal analysis of linguistic structures and 'substantive analysis of conceptual structures'. The present discussion owes much to Prandi's approach to the complexity of meanings.
} 


\section{Irreality and modality}

Bybee's proposal to reduce irreality to modality does not fully answer the problems raised by the of irreality. Indeed, in spite of the fact that modality and irreality are quite frequently paired together in the literature (Foley and Van Valin (1984), Chung \& Timberlake (1985), Palmer (2001), Narrog (2005, 2009) - see Pietrandrea 2005: 25ff for a review of these positions), some crucial differences exist between the two notions, no matter what definition of modality one subscribes to. Let us examine these differences.

Modality can be, first of all, regarded as a broad conceptual domain encompassing several partially parallel conceptual domains and therefore articulated according to agent-oriented, speaker-oriented, epistemic and subordinating modality, as proposed by Bybee $(1985,1998)$ and Bybee et al (1994). If one subscribes to this definition of modality, it emerges that non-actualization does not always belong to the conceptual structure of modalized SoAs. As pointed out by Pietrandrea (2005: 25ff), in fact, the non-actualization of the modalized SoA is always implied by epistemic (1) and speakeroriented modality (2), but it becomes sensitive to tense variations as far as agentoriented modality is concerned. As the comparison between (3) and (4) should make clear, the modalized SoA is put forward as non-actualized in agent-oriented modalized utterances describing present SoAs (3), whereas it may also be put forward as actualized in agent-oriented modalized utterances describing past SoAs (4):

(1) That meteorite must be from Mars' moon

(2) You must stop telling lies!

(3) He has to begin all over again

(4) He had to begin all over again [epistemic, non-actualized]

[speaker-oriented, non-actualized]

[agent oriented, non-actualized]

[agent oriented, actualized]

(from Pietrandrea 2005: 27)

An alternative definition identifies modality with the grammaticalization of the speaker's subjective attitude toward what she says (Lyons 1977, Palmer 1986, but also Halliday 1970 (1976)). This narrower definition excludes (or, at least, in order to be consistent should exclude - see Pietrandrea 2005: 13ff for a discussion) agent-oriented modality. This sub-sense of modality describes in fact objective, circumstantial, neutral situations of necessity (or possibility), rather than subjective attitudes. Thus, according to this definition, modality is reduced to speaker-oriented and epistemic, with the consequence that non actualization is always implied by the conceptual structure of the modalized SoA. This fact, however, is not sufficient reason to conclude that modality and irreality can be considered as one and the same notion. There is an important difference between the two: while modality explicitly expresses the presence of the speaker, being in other words subjective, performative or indexical (as the literature variously labels this important property of modality), irreality is not. Lyons writes on the subject:

Any utterance in which the speaker explicitly qualifies his commitment to the truth of the proposition expressed by the sentence he utters...is an epistemically modal, or modalized, utterance (italics ours).

(Lyons, 1977: 797)

When using a modal marker, the speaker explicitly expresses herself (her opinion, her will); this self-expression is part of the meaning of the modal and therefore it is intentional and uncancellable. On the contrary, self-expression of this kind is absent in irrealis markers, which simply qualify a SoA as being actualized or not. One may infer from the characterization of a SoA as non actualized that the speaker is only partially committed to the truth of the SoA, although this is a pragmatic inference; the irrealis marker per se does not say anything about the speaker as it is not intrinsically subjective, 
indexical, or performative. To sum up, the fact that irreality is not an intrinsically subjective notion is sufficient reason for distinguishing it from modality, at least considering the definition of modality that identifies it with the grammaticalization of the speaker's subjective attitude towards what she says.

An alternative view of modality is proposed by Narrog $(2005,2009)$, who describes modality neither in terms of agent-oriented, speaker-oriented and epistemic qualifications, nor in terms of subjectivity, but as "the linguistic category referring to the factual status of a state of affairs" (Narrog 2005: 184). Such a definition reduces modality to irreality and apparently solves the shortcomings mentioned above. However, it raises a major problem: it paradoxically obliges us to consider as modal a number of categories commonly associated cross-linguistically with irrealis markers, which are difficult to recognize as modals: conditionals, interrogatives, negatives, habituals, would therefore be considered modal categories (Pietrandrea 2005: 28).

To sum up, we may conclude with Plungian (2005: 141) that "irreality is closely related, but not at all identical with modality". In other words, the overlap between irreality and modality is largely imperfect and requires a distinction between the two notions that will be argued in the remaining part of this article.

\section{Irreality as a 'supercategory'}

Even though the differences between modality and irreality are clear, a temptation recurs in the literature to define irreality in modal terms. This emerges even in important works devoted to justifying the autonomy of reality status theoretically, which, in order to make clear what irrealis encodes, do not refrain from referring to the realm of speaker attitudes (imagination, knowledge, etc.), i.e. to the modal realm. Let us consider, for example, Mithun's (1999) and Elliot's (2000) definitions of reality status. Mithun writes:

"The realis portrays situations as actualized, as having occurred or actually occurring, knowable through direct perception. The irrealis portrays situations as purely within the realm of thought, knowable only through imagination ",

(Mithun 1999: 173)

\section{And Elliott:}

"A realis proposition prototypically asserts that an event or state in an actualised or certain fact of reality. An irrealis proposition prototypically implies an event belongs to the realm of the imagined or hypothetical, ${ }^{3}$ and as such it constitutes a potential or possible event but it is not an observable fact of reality".

(Elliot 2000: 66-67)

The refusal of reducing irreality to modality raises the question of how to define the non-actualization of a SoA conceptually in non-modal terms, i.e. without making reference to the speaker's attitude towards the proposition depicting that SoA.

Saying that a SoA is non-actualized means that it is presented as not grounded in perceivable reality. This may happen, in our view, for three quite different semantic purposes:

\footnotetext{
${ }^{2}$ Italics ours.

${ }^{3}$ Italics ours.
} 
(1) the SoA is qualified as not real, i.e. as not occurring or having occurred in the actual world: a negated SoA, for example. We propose to label this sense of irreality "counterfactuality";

(2) the SoA is put forward as just one of a set of mutually exclusive alternatives. The factuality of the SoA is not to be excluded among other alternatives. We propose to label this second sense of irreality "non exclusion of factuality or NEF";

(3) the SoA is introduced without specifying its spatio-temporal references in the actual world. The SoA may be an a-temporal generic or a habitual SoA. We propose to label this second sense of irreality "non-referentiality".

None of these three semantic qualifications is modal in nature. This is straightforward for counterfactuality and for non-referentiality; it also becomes clearer for NEF, when one thinks that introducing a SoA as but one of a set of mutually exclusive options does not serve the purpose of encoding the qualification of the speaker's commitment towards the truth of the proposition depicting that SoA, but permits the introduction of that SoA into the discourse independently of any commitment concerning the truth of the proposition expressing it (see $§ 5$ ).

What is also common to the three notions defined in this way is that they can be conceived as qualifications of the reality of the depicted SoA, rather than qualifications of the truth of the proposition representing that SoA. Using the terminology of Functional Grammar (Dik 1978, 1997; Hengeveld 1987,1988,1989, Dik \& Hengeveld 1991), thus, the indication of the irreality of a SoA is to be considered in any case as a predicational modifier operating on the SoA, rather than a propositional modifier, operating on the proposition (Dik \& Hengeveld 1991). This property further distinguishes irreality from at least that core part of modality represented by epistemic modality which is a propositional modifier by definition.

Thus, from a conceptual point of view marking the non actualization of a SoA is a multi-faceted operation. Irreality should not be regarded as the homogeneous value of the binary category of reality status, defined by the opposition between a [+ realis] and [-realis] value: in this respect we totally agree with Bybee (1998). This does not entail, however, that the very existence of a linguistically relevant conceptual notion of irreality should be discarded, as Bybee proposes. Rather, we claim that irreality should be viewed as a 'supercategory' (this label is sometimes used to refer to modality) encompassing several domains concerned with the qualification of the actualization of a SoA. From this standpoint, irreality is a conceptual notion as complex as the notion of modality, even though the two have to be distinguished. Given this conceptual complexity, one should expect that in the encoding of irreality languages exhibit the same complexity exhibited in the encoding of modality. It is entirely possible, for example, that a language dedicates a maximally under-specified marker to the expression of non-actualization, whatever the specification of this non-actualization might be. At the same time, there might be languages dedicating markers of 'irreality' to the expression of only one or other of the non-actualization sub-senses. The meaning of a marker dedicated to the expression of one of the sub-senses may be extended in some languages to indicate other sub-senses of non actualization. Irreality may variously interact with other contiguous categories. Only a bottom-up methodology, working from the description of single languages upwards, such as that suggested by DeHaan (2008) can thus foster our understanding of the expression of this semantic notion. 
An important issue to be dealt with concerns the attribution of situation types normally labelled as irrealis to one or other of the sub-senses of non-actualization. This is not a trivial issue.

One may be tempted to rely on intuition and to attribute, for example, negations and counterfactual hypotheses to counterfactuality, or hypothetical conditionals, concessive, optatives and epistemic modals to NEF, habitual and futures to non-referentiality.

This way of proceeding, however, is largely unsatisfactory. An intuition-driven approach, in fact, could at most indicate whether a given sense of non actualization is compatible with the conceptual structure of a situation type: it would not clarify whether that sub-sense is relevant for the way that conceptual structure is semanticized in a given language. This is a general problem in semantics. As observed by Ariel (2008: 87), there is "a tendency among semanticists to impose on linguistic semantic meanings all the elements necessary for the speaker's proposition to mesh with reality". However, "we cannot measure meaning [...] by consulting the objective reality behind our utterances" (Ariel 2008: 87). Not all the markers which refer to (and are compatible with) a given situation select the same aspects of that situation as linguistically relevant. In order to understand what is in the meaning of a marker it is not sufficient to inspect whether that marker is compatible with a situation and to include all the conceptual components of that situation in its meaning. Rather, it is necessary to distinguish all aspects, and only those aspects, of the situation made linguistically relevant by that marker, that is, intentionally communicated by speakers. Returning to our problem, for example, a 'logically irrealis' situation (as well as any situation) has a complex conceptual structure. This entails that in order to understand whether a sense of non actualization is linguistically relevant for the coding of one irrealis situation or the other - i.e. whether it should really be considered part of its linguistics meaning - it is not sufficient to observe whether it is conceptually consistent with that situation. On the contrary, it is necessary that one of the following two conditions hold:

(i) either the non-actualization sense under examination is a defining component of the conceptual structure of a given irrealis situation, i.e. that situation type cannot be defined without making reference to that sense;

(ii) or the non-actualization sense under examination is a conceptual component semantically focalized (through intentional mechanisms of explicit coding, conventional implicatures or invited inferences) in the way that situation is marked in a given language.

As far as the second of these conditions is concerned, it is clear that it can only be explored within a single language, supporting once again the bottom-up methodology suggested by DeHaan.

Needless to say, clear regularities are expected to emerge in the way these conceptual components are semanticized cross-linguistically and in the way they interact with one another: this prepares the ground for a proper typological analysis of the notion of irreality.

\section{NEF}

Given the complexity of the conceptual structure of irreality and the supposedly variable nature of its encoding cross-linguistically, we will limit the present inquiry to the analysis of the encoding of a single sense of irreality, NEF, in a single language, Italian. It will be shown that NEF is presupposed as a defining component or as a necessary condition for the communicative functioning of some typically irrealis situations 
(concessive conditionals and hypothetical conditionals, respectively). NEF is also encoded by some Italian constructions expressing other irrealis situations as an inherited conceptual defining component (counterfactual conditionals), or as a conventionally implicated component (some optative constructions, some directive constructions), or as an explicitly linguistically encoded notion (alternative relations). It will also be shown that NEF is conceptually compatible with epistemic modality, even though this notion does not tend to be linguistically marked or inferred from the encoding of epistemic modality.

\subsection{NEF in hypothetical conditionals}

Hypothetical conditionals are acknowledged in the literature to imply alternativity - and therefore NEF, as we will suggest - as a defining component of their conceptual structure.

Geis \& Zwicky (1971: 562) show that what they call "perfect conditionals", that is simple conditional constructions, are commonly interpreted in natural languages as "biconditionals". A conditional construction like (5) is not normally interpreted as a material implication simply stating that if it hails the harvest will be lost, without implying that something different will happen if it does not hail. On the contrary, constructions like (5) always contain an implicit component of biconditionality that imposes that their interpretation implies "not only that the second fact will happen if the first takes place, but also that the second will not happen if the first does not take place" (Prandi 2004: 44).

If it hails the harvest will be lost

Prandi (2004: 44-5) shows that this component of biconditionality has to be taken as an invited inference: it is automatically activated in any coherent communicative context, even though it can be cancelled in a conflicting environment, such as (6):

If it hails the harvest will be lost, and the same will happen if it does not hail.

What is important here is that the component of biconditionality is necessary to the successful communicative use of conditional constructions. As Prandi puts it:

"It is clear that the very act of uttering a conditional would be functionally unjustified, and therefore inconsistent as speech act, if the premise were really held to be irrelevant to the consequences. Thus, the plain fact that a conditional has been uttered justifies the addressee's assumption that the premise is not just a sufficient condition among others for the consequence, but rather a necessary - or at least salient - condition"

(Prandi 2004: 45)

According to Dancygier \& Sweetser (2005: 35), the communicative necessity of a biconditional interpretation of hypothetical conditional constructions, prompts hearers to construct not only a single 'mental space' involving the SoA depicted in the protasis and the SoA depicted in the apodosis, but also an alternative mutually exclusive 'mental space' involving the SoA negating the SoA depicted in the protasis and the SoA negating the SoA depicted in the apodosis. The relevance of hypothetical conditional constructions is based on the assumption of this alternativity: 
"A major class of conditional constructions conventionally express alternative based-predictions. They do this by expressing the correlation between an ifspace $\mathrm{P}$ and a situation $\mathrm{Q}$ which holds in $\mathrm{P}$. [...] Conditional predictions are relevant only via an assumption of alternativity between the if-space (where in $\mathrm{Q}$ is conditionally predicted) and some alternate space wherein $\sim \mathrm{P}$ holds, and therefore (since Q correlates specifically with P), Q holds as well)".

(Dancygier \& Sweetser 2005: 54-55)

Thus, in order to work properly, hypothetical conditional constructions need to mark, through an invited inference, the fact that the SoA depicted in the protasis belongs to a set of mutually exclusive SoAs. Putting forward the SoA depicted in the protasis as an option not to be excluded among others, therefore, is necessary for the successful communicative use of hypothetical conditionals as such (independent of its linguistic encoding).

This relevance emerges even more clearly in some marked conditional constructions. For example, in Italian, as well as in English, a post-posed protasis can be focused by quantificational focus markers such as solo 'only' (7) or except (8):

(7) Ci vado solo se tu vieni con me

'I will go there only if you go with me'

(8) I am not going except you go with me

(from Kortman 1997)

These focus markers relate the value of the focussed expression to a set of mutually exclusive alternatives (Nølke 1983, König 1991: 32, among others) through an uncancellable conventional implicature of biconditionality, as shown by König (1991: 57) and Prandi (2004: 44).

All in all, NEF is to be regarded as a defining component of the conceptual structure of hypothetical conditionals. Consequently, it must be considered part of their meaning.

\subsection{NEF in concessive conditionals}

$\mathrm{NEF}$ is a defining component of the conceptual structure of concessive conditional constructions. This major class of irrealis constructions has been identified by König and Haspelmath (1998), who define it as particular conditional constructions in which a set of protases depicting non factual alternative SoAs are related to an apodosis (Haspelmath and König 1998: 565). As Haspelmath and König observe:

"This set can be specified by some quantification over a variable in the protasis (universal concessive conditionals [see example (9)]), by a disjunction between a protasis $\mathrm{p}$ and its negation (alternative concessive conditionals [see example (10)]) or by characterizing the protasis as an extreme value for the relevant conditional sentence form (scalar concessive conditional [see example (11)])"

(Haspelmath and König 1998: 565)

The existence of a set of mutually exclusive conditions is a defining component of the conceptual structure in this class of conditional constructions. As shown by Haspelmath and König's (1998) cross-linguistic survey, languages tend to activate this conceptual component explicitly. Universal and scalar concessive conditionals are commonly marked through quantificational or scalar focus markers that refer to sets of mutually 
exclusive alternatives through uncancellable conventional implicatures: consider for example the English quantificational focus marker no matter in (9), or the English scalar focus marker even in (11). Alternative concessive conditionals are marked by alternative constructions that explicitly encode in a likewise uncancellable manner the existence of the set of mutually exclusive alternatives: see for example (10).

(9) No matter how much financial support we get, we will go ahead with our project

(10) Whether we get any financial support or not, we will go ahead with our project

(11) Even if we do not get any financial support, we will go ahead with our project

In some marginal, weakly grammaticalized cases, universal and scalar concessive may be marked by constructions that neither explicitly encode nor conventionally implicate alternativity, such as imperatives (12) or per/por/pour + ADJ constructions in Romance languages (13):

(12) Promettimi montagne d'oro, io non lo farò

'Even if you promise me [lit. promise.IMP.2SG+1SG.DAT] golden mountains, I won't do that'

(13) Per veloce che tu sia, non la puoi raggiungere

'However quick you are [lit. for quick you are], you cannot catch up with her'

(from Haspelmath and König 1998: 619)

Even in these cases, however, a component of scalarity is conventionally implied in order to make the construction work as a concessive conditional construction. As shown by König (1991: 64), in fact, the Gricean maxim of relevance requires that "if a conditional connection between two eventualities is asserted and presupposed, it is invariably the more remarkable case that it is asserted". In order to be activated as such, the conditional reading of the linking between the two SoAs in (12) (you promise golden mountains, I won't do that) and the two SoAs in (13) (you are quick, you cannot catch up with her), requires that the two conditioning SoAs (you promise golden mountains and you are quick, respectively) are presented as the most remarkable cases on some scale, i.e. on some ordered set of mutually exclusive options.

The bottom line is that, in order to be communicatively effective, the marking of concessive conditional constructions should focalize - mostly through explicit coding or conventional implicatures, - the existence of a set of mutually exclusive conditions. The factuality of the SoA depicted in the protasis is thus presented as not to be excluded among other options, which serves the purpose of conceding its factuality, without subscribing to it: also in this case, NEF is considered to be inscribed in the meaning of these constructions.

\subsection{NEF in Italian counterfactual conditionals}

While NEF is to be taken as a defining component of the conceptual structure of concessive conditionals and as a component necessary for the communicative effectiveness of hypothetical conditionals, the case of counterfactual conditionals is more problematic. As pointed out by Lazard (1998, 2006), in fact, counterfactual conditionals may be expressed through different means cross-linguistically: specific verb forms, context and/or the presence of a morpheme meaning 'if' and a protasis, past imperfective verb forms, verb forms combining an irrealis morpheme and a past morpheme. 
The conceptual structure of counterfactuality is thus differently focalized crosslinguistically. In order to understand whether NEF is linguistically relevant for counterfactuality, it is necessary to look at the way counterfactuality is expressed in a given language.

Thus, what will be argued in the following should be considered as restricted to Italian and other languages that use the same semantic strategy for the representation of counterfactuality.

Italian expresses counterfactuality combining the hypothetical conditional construction with past morphemes, which permits the combination of an irrealis, namely a NEF meaning with a past meaning. An example is in (14), in which the NEF meaning of the protasis is combined with the past tense expressed in the verb fossi:

\section{Se tu fossi venuto con me ci sarei andato}

'If you had [lit. be.SBJ.PST.2SG] come with me, I would have gone there'

As argued by Verstaete (2005) and Dancygier \& Sweetser (2005), the counterfactual meaning of this construction which is, by the way, quite widespread cross-linguistically - has to be understood as originating in an implicature triggered by the combination of past tense and irreality. In particular Verstraete, who uses the terms of 'non actualization' and 'potentiality' for what we call 'counterfactuality' and 'NEF' respectively, argues that:

"a feature of non actualization [i.e. counterfactuality, in our terminology] can originate as a generalized implicature of the feature of potentiality [NEF, in our terminology]: when located in a temporal domain that is inherently knowable and therefore within the realm of certainty, use of an expression of potentiality is in salient contrast with a more informative expression of certainty and therefore triggers the implicature that the event described did not take place, i.e. an implicature of non actualization."

(Verstraete 2005: 250-1)

Accepting Verstraete's argument, it is clear that NEF should be assumed as relevant in the case of counterfactual conditionals expressed through constructions combining ifprotasis and past tense such as (14), as inherited from hypothetical conditionals. The SoA depicted in the protasis is put forward as but one of a set of mutually exclusive alternatives occurring in the past. Since we assume that the past is known, the fact that the SoA depicted in the protasis is merely put forward as not to be excluded in the past triggers the implicature that it did not actually take place, i.e. the implicature of its counterfactuality.

Needless to say, other ways of expressing counterfactuality cannot be automatically taken as expressing NEF. One may hypothesize for example that languages that use specific verb forms for the expression of counterfactuality do not need to ground the marking of this meaning in the conflict between past and NEF meanings and they may also be marked by purely counterfactual markers not conveying NEF as an inherited component.

\subsection{NEF in (some) Italian Optatives}

To our knowledge, a complete typology of the strategies used to express the notion of optativity cross-linguistically is not provided in the literature. Dobrushina's et al (2005) chapter on optatives in the World Atlas of Linguistic Structures is deliberately restricted to the morphological expression of this notion and it disregards non inflectional means 
of expression of optativity, whose properties are just briefly outlined in more comprehensive analyses of imperatives and related categories (König and Siemund 2008, van der Auwera et al 2004). Given the scarcity of general knowledge about this notion, we can only attempt to identify its conceptual structure on the basis of the way it is encoded in Italian.

Optativity encodes the speaker's emotional appraisal of a situation seen as desirable. From a strictly conceptual point of view, the existence of a set of mutually exclusive SoAs, one of which is to be selected as desirable, is entirely compatible with the conceptual structure of optativity so characterized. Yet, the implication of the existence of this set of mutually exclusive SoAs cannot be regarded as a defining component of this conceptual structure. The expression of optativity can be obtained, in fact, through a focalization of the expression of the speaker's wish that a SoA becomes true, which does not encode, implicate, or invite the inference that the desired SoA belongs to a set of mutually exclusive alternatives.

Nevertheless, it may happen, at least in Italian, that the indication of desirability of the situation is linguistically encoded as an operation of selection among mutually exclusive alternatives. For example, this is the case with the optative meanings conveyed by constructions made up of exclusive focus markers - such as almeno 'at least', in (15), or se solo 'if only', in (16) - occurring with an exclamative intonational profile:

Almeno facesse una telefonata!

'If only he would make a phone call! [lit. at least he would make a phone call]'

\author{
Se solo smettesse di bere! \\ 'If only he would stop drinking!'
}

The exclamative context provides the frame to interpret the utterance as an expression of the speaker's appraisal of the depicted situation (Michaelis, 2001; König and Siemund 2008). The scalar exclusive focus markers almeno and se solo conventionally implicate the existence of a scale of mutually exclusive SoAs and mark the focussed one as the lowest in a scale of acceptability. In other words, they serve the purpose of depicting the factuality of the marked SoA as the lowest alternative not to be excluded as desirable on a scale of mutually exclusive SoAs.

These Italian optative constructions can, thus, be regarded as treating NEF as a linguistically relevant component of their conceptual structure.

\title{
4.5 NEF in polite directives (recommendations)
}

$\mathrm{NEF}$ is a conceptual component which is a compatible, but not a defining aspect in the conceptual structure associated with directive situations. It has been convincingly argued by Mauri \& Sansò (this volume - b) that three main conceptual components can be recognized in directive situations: (a) the speaker's wish that a SoA becomes true; (b) the appeal to the addressee to help make this SoA true; (c) the expectation that the desired SoA is brought about in the near future. Directive markers can focus on one or other of these components.

Mauri \& Sansò's (this volume - b) typological survey of the strategies used to mark directives reveals that directive markers diachronically derived from markers focalizing on the wish component of the conceptual structure of directives are often diachronically related to optative forms, from which - argue Mauri \& Sansò - they regularly inherit an irrealis nature. This kind of directive, unlike other directive markers (less regularly put forward as irrealis), does not indicate a high expectation of actualization of the marked SoA, neither does it depict the SoA as imminent. 
On the basis of the analysis of optatives conducted in $\S 4.4$, it can be suggested that this sub-class of directives could be seen as indicating operations of selection within sets of mutually exclusive SoAs to be accomplished by an addressee. This is the meaning for example of the directive in (17):

\section{Magari diglielo. Faglielo comunque capire che ci tieni a lui!}

'Maybe tell him. Anyway make him understand that you care about him'

In this utterance the Italian focus marker magari, etymologically related to the optative marker magari (Masini \& Pietrandrea in press, Pietrandrea 2008, see also §6 below) focuses on one of two formally encoded alternate directives (diglielo 'tell him', faglielo capire 'make him understand'), selecting the focused one as the SoA that the addressee should not exclude to make factual. This mild command has to be interpreted as a suggestion, or as what Paradis (2009) labels a recommendation.

Interestingly, Mithun (1995: 377) had already noted that, regarding imperatives, "many languages contain two options: a polite imperative, classified as irrealis, and a strong imperative, classified as realis". It is clear that recommendations, as operations of selection in sets of alternate SoAs to be accomplished by the addressee that do not indicate a high expectation of actualization of the marked SoA, can be viewed and rhetorically used as 'polite imperatives', i.e. imperatives leaving other 'choices' to the addressee.

\subsection{NEF and epistemic modality}

One unquestioned assumption in the study of the interaction between irreality and modality is that epistemic modality does refer to irrealis SoAs (see for example, Palmer 2001, Narrog 2005).

From a purely conceptual point of view this is trivial: the conceptual structure of epistemic modality is entirely compatible with the irreality of the depicted SoA, in particular with the non exclusion of its factuality. The fact that the speaker presents herself as only partially committed to the truth of a proposition implies that a proposition depicting a SoA alternative to the one depicted in the modalized proposition is not to be excluded.

The question arises to what extent a conceptual NEF component is linguistically relevant for the expression of epistemic modality: are there languages in which NEF is encoded in epistemic forms, or, at least, is it inferable through conventional implicatures or invited inferences from epistemic forms?

Surprisingly, the typological surveys so far conducted on irrealis (Elliott 2000, DeHaan, 2004, De Haan this volume, Lazard 1998) as well as the analysis of single languages (Chafe 1995, Mithun 1995, for example) rarely include epistemic modality in the number of categories marked as irrealis cross-linguistically. These studies show that some notions neighbouring epistemic modality, such as potentiality or possibility are indeed marked as irrealis, but the qualification of the speaker's commitment toward what she says as such is rarely reported to be marked as irrealis (the only two exceptions we can mention are the dubitative use of an irrealis morpheme in New Guinean languages (Bugenhagen 1994: 45, cited in DeHaan 2004) and the weak epistemic meaning of a bare irrealis construction in Nanti (reported by Michael 2008)).

In a diachronic analysis of the interaction between epistemicity and 'non-factuality' (i.e. irreality) in Romance languages, Squartini (in press) has shown that epistemicity is diachronically incompatible with non-factuality. Markers expressing the speaker's conjectural-inferential judgments towards the proposition, such as SEEM-verbs or the conjectural Future, in fact do not evolve towards markers of non-factuality. On the contrary, the reinforcing of the conjectural meaning of Italian Future has led to the 
dropping of the purely non factual meaning the Future could have in Old Italian. As shown by Squartini, the non-factual use of Future tense in (18) attested in the Novellino $\left(13^{\text {th }}\right.$ century) would be ungrammatical in contemporary Italian

(18) Scorseli la penna e scrisse CCC[...] il Saladino parlò: "Non dannare: scrivi CCCC. Per mala ventura se una tua penna sarà più lunga di me!" (Novellino) "His pen slipped and wrote CCC [...]. Saladin said: "Don't correct it: write CCCC. It would be a misfortune, if your pen were [lit. be.FUT.3SG] more generous than me"

(from Squartini, in press: 225)

Thus, it seems that the notion of NEF is neither explicitly encoded nor inferable to some degree of conventionality from epistemic forms. Rather, the non-exclusion-offactuality of the depicted SoA is better regarded as a side-effect of the marking of epistemic modality. Such a side-effect is in principle susceptible to be made linguistically relevant in some languages. Yet, the rarity of this inferential mechanism requires the clear conceptual distinction between epistemic modality - a core part of modality - and irreality argued for throughout this paper. ${ }^{4}$

On this basis, the suspicion arises that it would be better to regard the few cases where a marking of irrealis meaning on epistemic modality markers is recognized as cases where irrealis markers acquire an epistemic reading through a pragmatic inference. The fact that the speaker puts forward a SoA as not to be excluded may be pragmatically reinterpreted, in fact, as indicating that she is not fully committed to the truth of the proposition depicting that SoA. In this case, however, we don't have a truly epistemic marker encoding a NEF meaning, while we have an epistemic use of a NEF marker. Saying that this use proves the crucial importance of the NEF component for epistemic modality would be as awkward as saying that tense is crucial in epistemic modality given the frequent epistemic use of future.

\footnotetext{
${ }^{4}$ An anonymous referee points out that the notion of NEF corresponds to the notion of "non-factivity" largely employed by Lyons (1977) in his characterization of epistemic modality. The idea that NEF is simply a side effect of the marking of epistemic modality would therefore be contradicted by Lyon's classic analysis. A careful reading of Lyons' text suggests that the reason why he insists on the "non factivity" of epistemic modality is that he wants to distinguish the notion of epistemic modality employed in linguistics from the notion elaborated within logical frameworks. He says that epistemic logics deals with "the logical structure of statements which assert or imply that a particular proposition [...] is known or believed" (Lyons, 1977: 793). These statements include, in logics, also factive statements, such as "I know that p". What Lyons highlights is that, unlike philosophers, who include both factive and non factive statements in the domain of epistemic modality, linguists working on epistemic modality are mainly interested in "non factive predicators, like 'believe' or 'think' commit the speaker to neither the truth nor the falsity of the proposition expressed by their complement clauses" (Lyons, 1977: 795). He adds that these predicators "are typical of the utterance that linguists discuss in terms of the notion of epistemic modality; and we shall henceforth be concerned mainly with utterances of this kind" (Lyons 1977: 796). The fact that Lyons theoretically justifies his focus of non-factive utterances in the study of epistemic modality does not mean that he considers non factivity as the core of epistemic modality. He does not say this anywhere in his argumentation, nor in his definition of epistemic modality, which is put forward as the category dealing with "statements which assert or imply that a particular proposition is believed". In any case, we do not deny the fact that non-factivity is almost essential for the conceptual characterization of epistemic modality. Nevertheless it seems quite certain that most markers expressing epistemic modality do not semantically focalize this aspect of the conceptual structure of epistemic modality, but focalize the subjective commitment of the speaker. In other words, epistemic markers profile that the speaker has an opinion (and they leave in the background the fact that the content of this opinion is non-factual) rather than profiling that a given SoA is non-factual.
} 


\subsection{NEF in alternative relations}

The relevance of NEF for a number of notions usually labelled as irrealis lends further support to the hypothesis put forward by Mauri (2008b), who proposes including connectives coding alternative relations in the number of irrealis markers.

"...an irrealis marker has been defined as a marker which directly codes the irrealis status of the relevant SoA or which codes a notion implying that of irreality. The latter characterization of irrealis markers includes also connectives coding alternative, since they code a notion which implies the nonrealized status of the linked SoAs"

(Mauri 2008b: 177-78)

This proposal is grounded in a cross-linguistic survey of the marking of alternative relations, defined as the semantic relations "which obtain between two or more linked clauses expressing SoAs that constitute non co-occurring alternatives" (Mauri 2008a: 25). An example of alternative relation is in (19):

\section{Vengo a piedi, oppure prendo l'autobus}

'Either I walk or I take the bus'

What Mauri finds is that:

"in order to be presented as alternatives [...] SoAs need to be characterized in terms of possibility, either by means of a disjunctive connective or by means of already available irrealis markers"

(Mauri 2008a: 45)

In other words, not only disjunctive connectives, but also irrealis markers serve the purpose of presenting two or more SoAs as alternatives. This leads Mauri to postulate a relation between disjunctive connectives on the one hand and irrealis markers on the other: both serve to present the marked (or linked) SoAs as alternatives in virtue of their ability to characterize the SoAs in terms of 'possibilities' (i.e. as 'mutually exclusive options' in our terms). This relation is confirmed by a diachronic cross-linguistic analysis that shows that "many connectives coding alternative indeed originate from or evolve into irrealis markers" (Mauri 2008b: 181).

We have proposed above that a number of constructions expressing irrealis notions, such as conditionals, recommendations and optatives, either conventionally implicate or invite the inference that the factuality of the marked SoA is an option not to be excluded amongst the others. What disjunctive constructions do is to explicitly encode the existence of a set of mutually exclusive options. Within these constructions, the disjunctive connectives mark the option in their scope as not being excluded amongst others. They can be regarded therefore, on a par with conditionals, with (some) optative and with (some) recommendation markers, as NEF markers.

\section{The communicative use of $\mathrm{NEF}$}

As mentioned above, one of the arguments used by Bybee (1998) against the autonomy of irreality is that the notion of lacking in reality is not of much communicative use. Having split the notion of irreality into three more specific notions, counterfactuality, NEF and non-referentiality, we may raise the question of the communicative use of each of these notions, rather than the notion of lacking in reality in general. 
Focussing on NEF, we may ask what the communicative purpose of presenting a SoA as belonging to a set of mutually exclusive situations may be. We suggest that NEF fulfils the function of introducing SoAs into the discourse without thereby engaging the speaker to commit to the truth of the propositions describing them. NEF serves, in other words, to suspend the speaker's commitment to what she is saying. This communicative function needs to be marked somehow, since even a mere assertion presupposes the speaker's commitment to what she is saying. As Morency et al (2008) write, in fact:

"we can posit that when a speaker communicates a content $\mathrm{P}$ in the form of an assertion, she ipso facto communicates her commitment to P: otherwise this would yield a logical inconsistency"

(Morency et al 2008: 205)

Suspending commitment, thus, is quite an essential communicative function. This is logically necessary for the functioning of hypotheses, concessions and alternative relations, logically implied in optatives and rhetorically useful for recommendations. Suspending commitment, moreover, can also be used to invite the inference that the speaker is not fully committed to the truth of what she is saying, that is it may be used to invite the inference of an epistemic attitude of the speaker.

If our analysis is correct, we may claim that modality and irreality serve very different purposes: the former presupposes the existence of a commitment of the speaker and qualifies it, the latter cancels the speaker's commitment.

\section{NEF as a category}

Having identified the notion of NEF and its semantic and communicative properties, we can raise the question of the categoriality of this notion and ask whether and to what extent it can be considered as grammaticalized in a given language.

In order to be considered as grammaticalized in a given language, a semantic notion should satisfy two conditions: it should be conveyed by a dedicated form (that is a form whose central meaning is that of the notion in question, in our case a NEF meaning); the dedicated form conveying it should be a grammatical form (see, for example, Lazard's 2001 discussion on the categorical status of evidentiality).

Judgment concerning the satisfaction of the latter of these two conditions is clearly a matter of the theoretical approach adopted. The question of what is grammatical and grammaticalized is currently hotly debated. A more traditional approach considering as grammaticalized only affixed (or affixed-like) markers that belong to closed paradigms is currently facing the challenge launched by a new approach that considers as grammaticalized every relational meaning expressed by markers formally constrained at some constructional level (Bergs \& Diewald, 2008, Traugott 2007, Trousdale, 2008, but see also the special issue of the Italian Journal of Linguistics 19/1 2007 guest- edited by Mario Squartini, dedicated to "Evidentiality between lexicon and grammar").

We will not enter this debate here: we merely provide some data that can be interpreted in different ways, according to the theoretical approach adopted, showing that NEF does have a dedicated form in Italian and that this form is somehow constrained at an (albeit abstract) constructional level.

\subsection{An abstract construction for NEF}

Pietrandrea (2007) and Masini \& Pietrandrea (in press) have proposed that there exists in Italian a construction dedicated to expressing NEF meaning. 
In a general study of hedging strategies in spoken Italian, Pietrandrea (2007) has noted that the focus particle ${ }^{5}$ magari regularly takes in its focus items of different categorical status (arguments, predicates, adjuncts) that belong to lists of items realizing the same syntactic position. An example is given in the utterance (20), for which a 'grid representation' is also provided: ${ }^{6}$

(20) Che ne so poteva comparire una scenografia che che magari li riportava ne in un ambiente, in una foresta piuttosto che in una giungla nel deserto

'I don't know a set could appear that that maybe take them back in in a scene, in a forest rather than in a jungle, in the desert'

\begin{tabular}{|c|c|c|c|c|c|c|c|}
\hline 1 & $\begin{array}{l}\text { che ne so } \\
\text { 'I don't know' }\end{array}$ & $\begin{array}{l}\text { poteva comparire } \\
\text { 'could appear' }\end{array}$ & $\begin{array}{l}\text { una scenografia } \\
\text { 'a set' }\end{array}$ & $\begin{array}{l}\text { che } \\
\text { 'that' }\end{array}$ & & & \\
\hline 2 & & & & $\begin{array}{l}\text { che } \\
\text { 'that' }\end{array}$ & $\begin{array}{l}\text { magari } \\
\text { 'maybe' }\end{array}$ & $\begin{array}{l}\text { li riportava } \\
\text { 'take them back' }\end{array}$ & $\begin{array}{l}\text { ne } \\
\text { 'in' }\end{array}$ \\
\hline 3 & & & & & & & $\begin{array}{l}\text { in un ambiente } \\
\text { 'in a scene' }\end{array}$ \\
\hline 4 & & & & & & & $\begin{array}{l}\text { in una foresta } \\
\text { 'in a forest' }\end{array}$ \\
\hline 5 & & & & & $\begin{array}{l}\text { piuttosto che } \\
\text { 'rather than' }\end{array}$ & & $\begin{array}{l}\text { in una giunga } \\
\text { 'in a jungle' }\end{array}$ \\
\hline 6 & & & & & & & $\begin{array}{l}\text { nel deserto } \\
\text { 'in the desert' }\end{array}$ \\
\hline & & & & $\mathrm{ARG}_{1}$ & $\mathrm{ADJ}_{1}$ & $\mathrm{PRE}_{2}$ & $\mathrm{ARG}_{2}$ \\
\hline & $\mathrm{ADJ}_{1}$ & PRE & $\mathrm{ARG}_{1}$ & $\mathrm{ADJ}_{2}$ & & & \\
\hline
\end{tabular}

As highlighted by the grid representation, magari has, in this utterance, scope on the clause che li riportava in un ambiente 'that take them back them in a scene' and it focuses on the argument, in un ambiente 'in a scene' that belongs to a list of four arguments in un ambiente 'in a scene', in una foresta 'in a forest', in una giungla 'in a jungle', nel deserto 'in the desert'.

It may be the case that magari focuses on the entire clause: also in this case, the focussed clause is part of a list of clauses.

The tendency of magari to occur in list constructions such as the one represented in (20) has been confirmed by an analysis conducted by Masini \& Pietrandrea (in press) in

\footnotetext{
${ }^{5}$ By focus particles we intend with König (1991) and Nølke $(1983,2001)$ particles, such as the English also, even, only, or the French même, endowed with a remarkable syntactic mobility, having scope on a constituent and focusing on a part of it, interacting thereby with the focus structure of the sentence in which they occur.

${ }^{6}$ Grid representations are a powerful discourse representation device elaborated mainly by BlancheBenveniste et alii (1979), Bilger (1982), Blanche-Benveniste et alii (1990), Bilger et alii (1997), Gerdes \& Kahane (ms.), and Bonvino (2005), Pietrandrea (2008a), Masini \& Pietrandrea (in press) for Italian. This rewriting procedure consists of a representation of the speech flow on a bi-dimensional plane and is constrained by three simple rules: (i) the horizontal axis of the plane should feature the sequence of the positions that define the predicate-argument-adjunct structure; (ii) the vertical axis should list all the actual realizations within each position; (iii) a left-to-right and top-down reading of the string contained in the grid should render the linear order of the represented chunk. In this work, we basically use grid representations to provide a straightforward representation of the phenomena under discussion. A thorough theoretical account of the structures highlighted by this representation is provided by BlancheBenveniste et alii (1979), Bilger (1982), Blanche-Benveniste et alii (1990), Duvallon (2007), Gerdes \& Kahane (ms), Masini \& Pietrandrea (in press), among others.
} 
which a corpus of 600 written and spoken occurrences of magari revealed that this word is associated with list constructions in $64 \%$ of the cases.

This strong tendency induced Pietrandrea (2007) and Masini \& Pietrandrea (in press) to semantically characterize the construction magari + list as a NEF marker. Putting forward the item in the focus of magari as but one of a set of options, the speaker does not fully subscribe to the factuality of the SoA realized through that item; she simply does not exclude that that SoA could be factual among other options.

It is clear that the set of mutually exclusive SoAs defining a NEF meaning is in this case explicitly encoded in the list subpart of the construction.

\subsection{Specific NEF constructions}

The construction magari + list is in fact best viewed as an abstraction: this is a maximally abstract construction conveying a general non specified NEF meaning. What is found in Italian is a number of more specific constructions, all characterized by the presence of magari + list and all instantiating a particular NEF meaning. Masini \& Pietrandrea (in press) mention the following:

- an equipotential NEF construction

- a scalar NEF construction

- a scalar concessive conditional construction

- a weak command (recommendation) construction

and we may add:

- an alternative construction.

What distinguishes these constructions from one another is the specific form assumed by the list. Before examining each of these constructions in detail, it should be mentioned that the word magari also occurs in

- an optative construction

characterized by an exclamative intonational profile, whose NEF status is more doubtful, as will be argued below.

The abstract NEF construction can be instantiated by an "equipotential NEF" construction. In this case the factuality of the SoA realized through the focus of magari is put forward as not to be excluded on a par with the factuality of other options. This construction is characterized by the fact that magari focuses on an item occupying the top of a disjunctive list of items fulfilling the same syntactic position. This construction is represented in (21), where magari has scope on the entire clause and focuses on la corona Ibf 'the title Ibf', which is in an alternative relation with $o W b c$ 'or Wbc'. This produces the effect of putting forward the factuality of trying to obtain the Ibf title is not to be excluded on a par with the factuality of trying to obtain the Wbc title.

(21) Tenterò magari la corona Ibfo Wbc, insomma continuerò 'Maybe I will try (to win) the Ibf or Wbc title, in any cas I will go on' 


\begin{tabular}{|c|c|c|c|c|c|}
\hline 1 & & $\begin{array}{l}\text { Tenterò } \\
\text { 'I will try' }\end{array}$ & $\begin{array}{l}\text { magari } \\
\text { 'maybe' }\end{array}$ & $\begin{array}{l}\text { la corona } \\
\text { 'the title' }\end{array}$ & $\begin{array}{l}\text { Ibf } \\
\text { 'Ibf' }\end{array}$ \\
\hline 2 & & & $\begin{array}{l}\boldsymbol{o} \\
\text { 'or' }\end{array}$ & & $\begin{array}{l}W b c \\
\text { 'Wbc' }\end{array}$ \\
\hline \multirow[t]{3}{*}{3} & $\begin{array}{l}\text { insomma } \\
\text { 'in any case' }\end{array}$ & $\begin{array}{l}\text { Continuerò } \\
\text { 'I will go on' }\end{array}$ & & & \\
\hline & & & & $\mathrm{ARG}_{1}$ & $\mathrm{ADJ}_{1}$ \\
\hline & $\mathrm{ADJ}_{1}$ & PRE & $\mathrm{ADJ}_{2}$ & $\mathrm{ARG}_{1}$ & \\
\hline
\end{tabular}

The abstract NEF construction is also instantiated by a "scalar NEF" construction. In this case the SoA realized through the focus of magari is put forward as the last one whose factuality should not be excluded in a set of alternative options. This construction is characterized by the fact that the focus of magari occupies the bottom of a list of items having the same syntactic function. An example is in (22), where the SoA 'the movies have been approved from on high five times' is put forward as the last SoA for which the speaker would not exclude the factuality in the list of alternative SoAs 'the movies have been approved from high three times', 'the movies have been approved from high four times', 'the movies have been approved from high five times':

I film di oggi saranno stati approvati dall'alto tre, quattro, magari cinque volte 'Today's movies have been probably approved from on high three, four, maybe five times'

\begin{tabular}{|l||l|l|l|l|l|}
\hline 1 & $\begin{array}{l}\text { I film d'oggi } \\
\text { 'Today's movies' }\end{array}$ & $\begin{array}{l}\text { saranno stati approvati } \\
\text { 'have been probably approved' }\end{array}$ & $\begin{array}{l}\text { dall'alto } \\
\text { 'from on high' }\end{array}$ & & $\begin{array}{l}\text { tre } \\
\text { 'three' }\end{array}$ \\
\hline 2 & & & & $\begin{array}{l}\text { quattro } \\
\text { 'four' }\end{array}$ \\
\hline 3 & & & & $\begin{array}{l}\text { Magari } \\
\text { 'maybe' }\end{array}$ & $\begin{array}{l}\text { cinque volte } \\
\text { 'five times' }\end{array}$ \\
\hline & & & & $\mathrm{ADJ}_{1}$ & $\mathrm{ADJ}_{2}$ \\
\hline & $\mathrm{ARG}_{1}$ & $\mathrm{PRE}$ & $\mathrm{ADJ}_{1}$ & $\mathrm{ADJ}_{2}$ & \\
\hline
\end{tabular}

The abstract NEF construction can be instantiated sometimes by a "scalar concessive conditional construction". In this case, the speaker asserts the factuality of a SoA, even not excluding the factuality of the SoA realized through the focus of magari. The latter SoA is presented as the most unlikely and most adverse condition for the realization of the asserted SoA. In this construction magari focuses on the first item of a list of conjuncts depicting a contrast relation. An example of this function is in (23):

Ce la mettono tutta, magari scrivono anche bei pezzi. Ma sono troppo limitati 'They do their best, they may also write beautiful pieces, but they are too limited' 


\begin{tabular}{|l|l|l|}
\hline 1 & & $\begin{array}{l}\text { ce la mettono tutta } \\
\text { 'they do their best' }\end{array}$ \\
\hline 2 & $\begin{array}{l}\text { magari } \\
\text { 'maybe' }\end{array}$ & $\begin{array}{l}\text { scrivono anche bei pezzi } \\
\text { 'they also write beautiful pieces' }\end{array}$ \\
\hline 3 & $\begin{array}{l}m a \\
\text { 'but' }\end{array}$ & $\begin{array}{l}\text { sono troppo limitati } \\
\text { 'they are too limited' }\end{array}$ \\
\hline & ADJ & CLAUSE \\
\hline
\end{tabular}

In (23), magari focuses on the clause scrivono anche bei pezzi 'they write beautiful pieces', connected through the adversative conjunction $m a$ 'but' with the clause sono troppo limitati 'they are too limited', which describes a factual SoA. The contrastive connection between a non-factual SoA and a factual SoA yields a non-factual concessive meaning in Italian. In (24) an example of such a construction, realized through an irrealis marker other than magari, is provided:

\section{Può essere che è intelligente, però non lo dimostra}

'It is possible that she is clever, but she does not show it'

What magari adds to this construction is its scalar meaning: magari evokes a set of conditions and it marks the condition in its focus as the most unfavorable and the most unlikely (the last one whose factuality can be not excluded) for the realization of the SoA depicted in the factual clause. The scalarity of magari can be either formally realized - as in (23), where magari focuses on the last conjunct of two clauses ce la mettono tutta 'they do their best', scrivono anche bei pezzi 'they also write beautiful pieces' - or encoded through an invited inference. ${ }^{7}$ The scalar concessive conditional construction inherits from the scalarity of magari its NEF semantic component. The SoA realized through the focus of magari is put forward as the last condition whose factuality can be not excluded in an ordered set of conditions in order to preserve the factuality of a contrasting SoA.

The NEF construction is also instantiated by "recommendation constructions". These constructions, characterized by magari focusing on the first (or the last) of a list of imperatives, present the order in the focus of magari as not to be excluded (either on a par with other options -when magari focuses the first of a list of imperatives - or as the last one not to be excluded -when magari focuses the last of a list of imperatives). An example is in (25), where the imperative in the focus of magari is put forward as the last SoA the addressee should not exclude performing:

(25) Prova a calmarti un po' [...], magari chiedi scusa alla mamma

'Try to calm down a bit and possibly apologize to your mother'

\begin{tabular}{|l|l|l|l|l|}
\hline 1 & & $\begin{array}{l}\text { Prova } \\
\text { 'try' }\end{array}$ & $\begin{array}{l}\text { a calmarti } \\
\text { 'to calm down' }\end{array}$ & $\begin{array}{l}\text { un po' } \\
\text { 'a bit' }\end{array}$ \\
\hline 2 & $\begin{array}{l}\text { magari } \\
\text { 'possibly' }\end{array}$ & $\begin{array}{l}\text { chiedi scusa } \\
\text { 'apologize' }\end{array}$ & $\begin{array}{l}\text { alla mamma } \\
\text { 'to your mother' }\end{array}$ & \\
\hline & $\mathrm{ADJ}_{1}$ & PRE & $\mathrm{ARG}_{1}$ & $\mathrm{ADJ}_{2}$ \\
\hline
\end{tabular}

\footnotetext{
${ }^{7}$ As was shown in $\S 4.2$, in fact, in order to conform to the maxim of Relevance, magari, as well as other focus particles, always acquires a scalar meaning in conditional concessive contexts.
} 
A final instantiation of the abstract NEF construction, not discussed by Masini \& Pietrandrea (in press) is the magari disjunctive construction. This construction is used to mark the existence of an alternative relation between a number of items in a list. Each of these items is focalized by an occurrence of magari. An example is in (26):

Magari è lì da un attimo magari è lì da sempre

'maybe he's been there for a second, maybe he's been there forever'

[from Alessandro Baricco, Oceano Mare, Milan, BUR, 1999]

\begin{tabular}{|l|l|l|l|l|}
\hline 1 & $\begin{array}{l}\text { magari } \\
\text { 'maybe' }\end{array}$ & $\begin{array}{l}\grave{e} \\
\text { 'he's been' }\end{array}$ & $\begin{array}{l}\text { lì } \\
\text { 'there' }\end{array}$ & $\begin{array}{l}\text { da un attimo } \\
\text { 'for a second' }\end{array}$ \\
\hline 2 & $\begin{array}{l}\text { magari } \\
\text { 'maybe' }\end{array}$ & $\begin{array}{l}\grave{e} \\
\text { 'he's been' }\end{array}$ & $\begin{array}{l}\text { lì } \\
\text { 'there' }\end{array}$ & $\begin{array}{l}\text { da sempre } \\
\text { 'forever' }\end{array}$ \\
\hline & & PRE & $\mathrm{ARG}_{1}$ & $\mathrm{ADJ}_{2}$ \\
\hline & $\mathrm{ADJ}_{1}$ & CLAUSE & \\
\hline
\end{tabular}

In this construction, the factuality of each item is presented as not to be excluded. The overall effect is the coding of a set of mutually exclusive SoAs. The coding of alternative relations through markers of irreality is in fact, quite widespread, as Mauri's (2008a, 2008b) studies make clear.

It has been shown so far that Italian has an abstract constructional marker dedicated to the expression of NEF and that this constructional marker is instantiated by a number of specific constructions, each conveying a particular NEF meaning.

Interestingly, these constructions can be unified with other Italian constructions that have semanticized a NEF component in their meanings (see above \$4), such as hypothetical conditional constructions (27) and counterfactual constructions $(28)^{8}$ :

(27) Se fosse bello o se magari fossi più brillante, me ne innamorerei

If he were handsome or, at least, more brilliant [lit. or if magari were more brilliant], I would just fall in love with him

(28) Se la protagonista non fosse stata così ingenua e remissiva, e se ne fosse andata via finché poteva da quella cittadina così palesemente ipocrita e meschina, o se magari avesse subito imposto la sua presenza con una buona dose di sana arroganza, forse non si sarebbe giunti a quel punto.

If the protagonist had not been so naive and remissive and if she had left when she still could from that so clearly hypocritical and closed-minded town, or, at any rate, if she had imposed her presence [lit. or if magari she had imposed her presence] with a good dose of sound arrogance, probably we wouldn't have arrived to this situation.

It should also be mentioned that the word magari occurs, albeit more rarely, in a different construction characterized by an exclamative context and the absence of a list construction. This construction conveys an optative meaning. An example is in (29):

\footnotetext{
${ }^{8}$ The long excerpt in (28) has been purposely chosen to show that a construction characterized by a list can even span an entire text (for details on the theoretical relevance of this fact, see Duvallon 2006, Pietrandrea 2007, Masini \& Pietrandrea in press).
} 
The question arises whether such an optative construction can be seen as having semanticized a NEF component in its meaning.

This may be plausible to a certain extent. As mentioned in $\$ 4.4$, in fact, a NEF component can be seen as a part of the meaning of optative constructions when they are put forward as operations of selection within sets of mutually exclusive SoAs. However, all the magari NEF constructions so far examined are characterized by the presence of a list that explicitly codes the set of mutually exclusive options implied by the non exclusion of factuality operation.

In the case of optative magari, the list is absent. We should therefore exclude that NEF meaning is encoded in this construction.

An alternative interpretation, however, may be proposed if one takes into due consideration the fact that NEF optatives are to be regarded as selection operators. If an optative marker serves to select an option in a set, it is quite obvious that only the selected option is linguistically realized, while the set of other options remains simply presupposed.

Such a hypothesis is lent some support by various historical facts studied by Pietrandrea (2008b). The word magari was only used until $19^{\text {th }}$ century as an optative marker. The coalescence of magari with list constructions caused and reinforced the bleaching of its meaning toward general non-factuality. The explanation Pietrandrea (2008b) provides for this phenomenon is that the explicit mention of more than one option in the focus of magari weakened its function of selector and therefore its proper optative meaning.

If this hypothesis is correct, we may propose that the optative magari presents (as well as the optative constructions realized through the focus particles se solo, almeno, described in §4.4) a NEF component in its meaning, even though the set of other options (among which the non exclusion of the factuality of the focus of magari is indicated as to be preferred) is merely presupposed, rather than formally realized.

Essentially, Italian has a complex and abstract constructional marker dedicated to the expression of NEF meaning; this abstract construction is instantiated by (or unificated with) a number of more specific constructions used to refer to various situation types having NEF as a semantic component: ENEF constructions, scalar NEF constructions, scalar concessive conditional constructions, recommendation constructions, disjunctive constructions, hypothetical conditional constructions, counterfactual conditional constructions and (probably) optative constructions.

\subsection{Is the NEF construction 'grammatical'?}

We have mentioned in $\S 6$ that in order to be considered a proper grammatical category of a language, a semantic notion should be expressed by a dedicated form in that language and that this form should be grammatical.

The analysis conducted so far shows that the former of the two conditions is satisfied.

The question which remains to be inquired is whether the NEF magari construction is a grammatical marker. As mentioned above, the answer to this question can only be provided by the theoretical definition of grammatical construction that one subscribes to.

We can certainly exclude that the complex construction dedicated to mark NEF meaning in Italian is an affixed or affixed-like marker in a clear paradigmatic opposition with other markers of reality status. This means that the NEF construction cannot be 
considered as proper grammatical if one subscribes to a narrow view of what a grammatical marker is.

An alternative view on this matter has been proposed by Pietrandrea (2007) who sees an analogy between the affixation of morphemes conveying grammatical meaning to stems and the coalescence of markers conveying grammatical (i.e. abstract, relational) meaning - such as the word magari - to complex constructions. In both cases, a unit conveying a grammatical meaning shows a reduced syntagmatic mobility. This fact can be interpreted as a reduction of the autonomy of that unit, which is taken to correlate positively with its grammaticalization (see for example, Lehmann 1985).

Adopting such a view, the grammatical nature of the NEF construction could be argued. Such a hypothesis would be lent further support if future research proves that the encoding of meanings is regularly made at an abstract and complex constructional level such as the one detected in the present analysis. ${ }^{9}$ In this case in fact, the NEF magari construction could be regarded as integrated within an albeit very abstract paradigm of similarly behaving constructions, rather than being an isolated phenomenon.

Nothing more can be said at the moment.

\section{Conclusions}

The present analysis has shown that irreality cannot be reduced to modality. In order to define irreality in non modal terms, we have suggested that this notion is best viewed as a supercategory encompassing at least three domains related to the indication of the non actualization of a SoA: counterfactuality, NEF and non-referentiality. The conceptual complexity of what is commonly labeled as 'irreality' is mirrored by the complexity of the conceptual structure of what are commonly defined 'logically irrealis situation types'. Languages do not semanticize the whole conceptual complexity of a situation type: they arbitrarily select the conceptual components to be made linguistically salient. If this overall complexity is not taken into the due account, and one merely limits oneself to considering on the one hand irreality as one of the two values of the binary category of reality status and on the other hand logically irrealis situation types as situations to be characterized as irrealis no matter how their conceptual structure is semanticized in a given language, a number of misalignments will obviously result.

We adopted therefore a more analytical approach and studied in depth the expression of a single irrealis value, NEF, in a single language: Italian. We conformed in this way to the bottom-up approach to the analysis of irrealis suggested by De Haan (this volume).

Our analysis has shown that NEF is a defining component of the notion of concessive conditional, that the inference of a NEF component is necessarily invited in order to make hypothetical conditionals communicatively effective, that a NEF component is inherited by counterfactual hypothetical conditional constructions in Italian, that some Italian optative and polite directive constructions conventionally implicate a NEF component and finally that NEF is explicitly encoded in disjunctive constructions. We have argued that NEF has a precise non-modal communicative function: it serves to introduce SoAs into the discourse exempting at the same time the speaker from committing to the truth of the proposition conveying that SoA. In other words, NEF serves to cancel the speaker's commitment towards what she is saying (rather than to qualify it, as modality does).

Studying the expression of NEF in Italian, we have shown that this language has an abstract complex constructional marker specifically dedicated to encode NEF meaning

\footnotetext{
${ }^{9}$ See in this respect, Mauri's (2008a and 2008b) studies on coordinative constructions, and in particular Mauri's hypothesis of the encoding of irrealis meaning at the inter-clause level.
} 
that is instantiated in (or unified with) a number of NEF constructions: ENEF, scalar $\mathrm{NEF}$, scalar concessive conditionals, recommendations, constructions coding alternative relations, hypothetical conditionals, counterfactual conditionals, and, perhaps, optative constructions.

We could neither exclude the grammaticality of this construction, nor prove it. More research is needed to inquire into whether the expression of reality status is regularly conveyed by complex constructional markers and to establish precisely the conditions that need to be satisfied in order to consider a complex constructional marker as grammatical.

\section{Acknowledgments}

This research was carried out as part of the TopoGram project (Università Roma Tre) on the topology of grammatical meaning in discourse constructions. I would like to express my gratitude to Caterina Mauri and Andrea Sansò for their comments, for their suggestions, for their patience, for their friendship. I also thank the anonymous referee, whose comments have undoubtedly improved the paper. Special thanks go to Mario Squartini, who still agrees to negotiate the boundaries of modality (and related categories) with me. This paper could not have been written without the many fruitful exchanges I have had with Francesca Masini and without the ever-inspiring guidance of Claire Blanche-Benveniste. The usual disclaimers apply.

\section{References}

Ariel M., (2008). Pragmatics and Grammar. Cambridge University Press, Cambridge

Bergs, A. and G. Diewald, (Eds.), 2008. Constructions and Language Change. Mouton de Gruyter, Berlin.

Bilger, M., 1982. Contribution à l'analyse en grille. Recherches sur le français parlé 4, 195-215.

Blanche-Benveniste, C., B. Borel, J. Deulofeu, J. Durand, A. Giacomi, C. Loufrani, B. Meziane \& N. Pazery, 1979. Des grilles pour le français parlé. Recherches sur le français parlé 2, 163-205.

Blanche-Benveniste, C., M. Bilger, Ch. Rouget \& K. Van den Eyende, 1990. Le français parlé. Etudes grammaticales. Editions du Centre National de la Recherche Scientifique, Paris.

Bonvino, E., 2005. Le sujet postverbal en italien parlé: syntaxe, zones et intonation. Bibliothèque des faits des langues, Ophrys, Paris.

Bugenhagen, R. D., 1994. The semantics of irrealis in the Austronesian languages of Papua New Guinea. In Ger. P. Reesink (Ed.), Topics in descriptive Austronesian linguistics. Rijksuniversiteit Leiden, Leiden.

Bybee, J., 1985. Morphology: A study of the relation between meaning and form. Benjamins, Amsterdam/Philadelphia.

Bybee, J., 1998. Irrealis as a grammatical category. Anthropological Linguistics 40, 257-271. 
Bybee, J., R. Perkins \& W. Pagliuca, 1994. The evolution of grammar: tense, aspect and modality in the language of the world. University of Chicago Press, Chicago.

Chafe, W., 1995. The Realis-Irrealis Distinction in Caddo, the Northern Iroquoian languages, and English. In Bybee J. and S. Fleischman (Eds.), Modality in Grammar and Discourse. Benjamins, Amsterdam/Philadelphia, pp. 349-366.

Chung, S. and A. Timberlake, 1985. Tense, Aspect and Mood. In Shopen, T. (Ed). Language Typology and Syntactic Description, III. Grammar Categories and the Lexicon. Cambridge University Press, Cambridge, 202-258.

De Haan, F., 2004. On representing semantic maps (ms.). University of Arizona

De Haan, F., this volume. Irrealis: fact or fiction

Dancygier, B. and E. Sweetser, 2005. Mental spaces in grammar. Cambridge University Press, Cambridge.

Dik, S. C., 1978. Functional Grammar. North Holland Publishing Company, Amsterdam.

Dik, S. C., 1997. The Theory of Functional Grammar, I. The Structure of the Clause, (edited by K. Hengeveld), Mouton de Gruyter, Berlin.

Dik, S. C. and K. Hengeveld, 1991. The hierarchical structure of the clause and the typology of perception-verb complements. Linguistics 29, 231-59.

Dobrushina, N., J. van der Auwera and V. Goussev, 2005. Optative. In: Dryer M., M. Haspelmath, D. Gil and B. Comrie. World Atlas of Language Structures. Oxford University Press, Oxford.

Duvallon, O., 2006. Le pronom anaphorique et l'architecture de l'oral en finnois et en français. Bibliothèque finno-ougrienne, L'Harmattan, Paris.

Elliott, J. R., 2000. Realis and Irrealis: Forms and Concepts of the Grammaticalization of Reality. Linguistic Typology 4, 55-90.

Foley, W. A. \& R. D. VanValin, 1984. Functional Syntax and Universal Grammar. Cambridge University Press, Cambridge.

Geis, M. L. and A. M. Zwick, 1971. On invited inferences. Linguistic Inquiry 2, 561566.

Gerdes, K. and S. Kahane, to appear. Speaking in Piles - Paradigmatic Annotation of a Spoken French Corpus. In: Proceedings of the fifth Corpus Linguistics Conference, Liverpool.

Halliday, M. A. K. 1970 (1976 [1987]). Functional Diversity in Language as Seen from a Consideration of Modality and Mood in English. Foundations of Language 6, 322365; reprinted in Halliday M. A. K. 1976 [1987]. System and Function in Language. Selected Papers (edited by G.R. Kress), Oxford University Press, Oxford. 
Haspelmath, M. and E. König, 1998. Concessive conditionals in the languages of Europe. In: van der Auwera, Johan (ed.) Adverbial constructions in the languages of Europe. (Empirical Approaches to Language Typology/EUROTYP, 20-3.) Mouton de Gruyter, Berlin 563-640.

Hengeveld, K., 1987. Clause Structure and Modality in Functional Grammar. In van der Auwera J. - Goossens L. (Eds.). Ins and Outs of the Predication, Foris, Dordrecht, pp. 53-66.

Hengeveld, K., 1988. Illocution, Mood and Modality in a Functional Grammar of Spanish. Journal of Semantics 6, 227-269.

Hengeveld, K., 1989. Layers and Operators in Functional Grammar, Journal of Linguistics, 25 127-157.

König, E., 1991. The meaning of focus particles: A comparative perspective. Routledge, London.

König, E. and P. Siemund, 2007. Speech Acts Distinctions in Grammar. In Shopen, T. (Ed.), Language Typology and Syntactic Description. Vol. I: Clause Structure (2nd edition). Cambridge University Press, Cambridge, pp. 276-304.

Kortmann, B., 1997. Adverbial Subordination. A typology and history of adverbial subordinators based on European languages. Mouton de Gruyter, Berlin.

Lazard, G., 1998. L'expression de l'irréel: essai de typologie. In Kulikov, L. and H. Vater (Eds.), Typology of Verbal Categories: Papers Presented to Vladimir Nedjalkov on the Occasion of his 70th Birthday. Max Niemeyer, Tübingen, pp. 237-248.

Lazard, G., 2001. On the Grammaticalization of Evidentiality. Journal of Pragmatics 33, 339-348.

Lazard, G., 2006. More on counterfactuality, and on categories in general. Linguistic Typology 10(1), 61-66.

Lehmann, C., 1985. Grammaticalization: Synchronic Variation and Diachronic Change. Lingua e Stile 20(3), 303-319.

Lyons, J., 1977. Semantics, vol 2. Cambridge University Press, Cambridge.

Masini, F. and Pietrandrea P. 2010. Magari. Cognitive Linguistics 21.1.

Mauri, C., 2008a. The irreality of alternatives: towards a typology of disjunction. Studies in Language 32(1), 22-55.

Mauri, C., 2008b. Coordination relations in the Languages of Europe and Beyond. Mouton de Gruyter, Berlin/New York.

Mauri, C. and A. Sansò, this volume a??? Introduction 
Mauri, C. and A. Sansò, 2008b. ??? The reality status of directives and its coding across languages

Michael, L., 2008. The morphosyntax and semantics of realisness in Nanti (Arawak, Peruvian Amazonia). Paper delivered at the workshop "What do languages code when they code Realisness?" Theme session of the - 41st annual meeting of the Societas Linguistica Europaea Forlì, 17-20 September 2008.

Michaelis, L. A., 2001. Exclamative Constructions. In M. Haspelmath, E. König, W. Österreicher and W. Raible (Eds.), Language Universals and Language Typology: An International Handbook. Walter de Gruyter, Berlin, pp. 1038-1050.

Morency, P., S. Oswald and L. de Saussure, 2008. Expliciteness, implicitness and commitment attribution: A cognitive pragmatic approach. Belgian journal of linguistics 22, 197-220.

Mithun, M., 1995. On the Relativity of Irreality. In Bybee J. and S. Fleischman (Eds.), Modality in Grammar and Discourse. Benjamins, Amsterdam/Philadelphia, pp. 367388.

Mithun, M., 1999. The Languages of Native North America. Cambridge University Press, Cambridge.

Narrog, H., 2005. On defining modality again. Language Sciences 27(2), 165-192.

Nølke, H., 1983. Les adverbes paradigmatisants: fonction et analyse. Akademisk Forlag, Copenaghen.

Nølke, H., 2001. Le regard du locuteur 2 : Pour une linguistique des traces énonciatives. Kimé, Paris.

Palmer, F. R., 1986. Mood and Modality. Cambridge University Press, Cambridge.

Palmer, F. R., 2001. Mood and Modality. 2nd Edition. Cambridge University Press, Cambridge.

Paradis, C., 2009. This beauty should drink well for 10-12 years: a note on recommendations as semantic middles. Text \& Talk 29 (1), 53-73.

Pietrandrea, P., 2005. Epistemic Modality. Functional Properties and the Italian System. Benjamins, Amsterdam/Philadelphia.

Pietrandrea, P., 2007. The grammatical nature of some epistemic-evidential adverbs in spoken Italian. Italian Journal of Linguistics 19(2), 39-64.

Pietrandrea, P., 2008a. Certamente and Sicuramente. Encoding dynamic and discursive aspects of commitment in Italian. Belgian Journal of Linguistics 22, 221-246.

Pietrandrea, P., 2008b. Constructionalization, grammaticalization and discourse: the case of magari. Paper delivered at New Reflection on Grammaticalization 4 Conference, Leuven 16-19 july 2008. 
Plungian V., 2005. Irrealis and modality in Russian and in typological perspective. In B. Hansen, and P. Karlík (eds.): Modality in Slavonic Languages. New Perspectives. München: Sagner 2005, 135-146.

Prandi, M., 2004. The Building Blocks of Meaning. Amsterdam: Benjamins, Amsterdam/Philadelphia.

Squartini, M., (2009). Evidentiality, epistemicity and their diachronic connections to non-factuality. In Maj-Britt Mosegaard Hansen and Jacqueline Visconti (Eds.), Current Trends in Diachronic Semantics and Pragmatics. Emerald: Oxford.

Traugott, E., 2007. The concepts of constructional mismatch and type-shifting from the perspective of grammaticalization. Cognitive Linguistics 18(4), 523-557.

Trousdale, G., 2008. A constructional approach to lexicalization processes in the history of English: Evidence from possessive constructions. Word Structure 1(2), 156-177.

Van der Auwera, J., N. Dobrushina and V. Goussev, 2004. A Semantic Map for Imperative-Hortatives. In Willems D., B. Defrancq, T. Colleman and D. Noël (Eds.) Contrastive Analysis in Language. Identifying Linguistic Units of Comparison. Palgrave Macmillan, Basingstoke, pp. 44-66.

Verstraete, J. C., 2005. The semantics and pragmatics of composite mood marking: The non-Pama-Nyungan languages of northern Australia. Linguistic Typology 9, 223-268. 